\title{
Investigation of each histological type in undifferentiated early gastric cancer and validity of diagnosis of the disease range
}

\author{
Yoshikazu Yoshifuku $^{1} \cdot$ Yoji Sanomura ${ }^{2} \cdot$ Shiro Oka $^{2} \cdot$ Shinji Tanaka $^{2} \cdot$ \\ Kazuaki Chayama ${ }^{1}$
}

Received: 17 September 2015/ Accepted: 2 November 2015/Published online: 19 November 2015

(c) The International Gastric Cancer Association and The Japanese Gastric Cancer Association 2015

To the editor

We read with interest the article entitled "Accuracy of diagnostic demarcation of undifferentiated-type early gastric cancers for magnifying endoscopy with narrow-band imaging: endoscopic submucosal dissection cases" by Horiuchi et al. [1]. The authors determined demarcation lines of undifferentiated (UD)-type early gastric cancer (EGC) by using magnifying endoscopy with narrow-band imaging (ME-NBI) and marking the utmost oral and anal sites of the lesion using argon plasma coagulation. After performing endoscopic submucosal dissection (ESD), they evaluated the rate of accurate diagnosis by defining it as the consistency of the utmost oral and anal demarcation lines of the lesion with the postoperative pathological findings. As a result, the rate of accurate diagnosis was $81.6 \%$, and the authors concluded that the use of ME-NBI in the

This comment refers to the article available at doi:10.1007/s10120015-0488-x.

Yoji Sanomura

y-sanomura@hiroshima-u.ac.jp

1 Department of Gastroenterology and Metabolism, Graduate School of Biomedical Sciences, Hiroshima University, Hiroshima, Japan

2 Department of Endoscopy and Medicine, Graduate School of Biomedical Sciences, Hiroshima University, Hiroshima University Hospital, 1-2-3 Kasumi, Minami-Ku, Hiroshima 734-8551, Japan diagnostic demarcation of UD-type EGC should be recommended. However, we have several questions.

The first concerns the histologic type of UD-type EGC. There are several histologic types, such as signet ring cell carcinoma, poorly differentiated adenocarcinoma, mucinous adenocarcinoma, and mixed type [2]. Choi et al. [3] reported that the rate of lateral margin positivity in both poorly differentiated adenocarcinoma and poorly differentiated adenocarcinoma with signet ring cell features was significantly higher than that for signet ring cell carcinoma alone. Thus, there might be a difference among histologic types of UD-type EGC when calculating the rate of accurate diagnosis based on the demarcation line. Did the authors investigate the differences of each histological type? In addition, the findings of ME-NBI for each histological type were also considered interesting and useful for the actual clinical practice. Therefore, these results should be suggested additionally. Were there any differences in endoscopic images when using ME-NBI in each histological type?

The second question relates to the diagnosis based on the demarcation lines before ESD. The authors reported that $81.6 \%$ of the EGCs could be correctly diagnosed on the basis of demarcation lines by using ME-NBI. However, it seems that this accuracy is not enough when diagnosing the range of EGCs appropriate for ESD. Generally, UDtype EGC has been reported as being at high risk for lateral margin positivity following ESD [4-6]. Therefore, we always perform a biopsy to determine negative margins around the lesion before ESD for UD-type EGC. Do the authors determine the cutting line before ESD only by using ME-NBI without negative biopsy?

We hope this letter will contribute to the further understanding of gastric cancer and to the fruitful growth of gastric cancer research. 


\section{Compliance with ethical standards}

\section{Conflict of interest None.}

\section{References}

1. Horiuchi Y, Fujisaki J, Yamamoto N, Shimizu T, Miyamoto Y, Tomida $\mathrm{H}$, et al. Accuracy of diagnostic demarcation of undifferentiated-type early gastric cancers for magnifying endoscopy with narrow-band imaging: endoscopic submucosal dissection cases. Gastric Cancer. 2015. doi:10.1007/s10120-015-0488-x.

2. Oka S, Tanaka S, Higashiyama M, Numata N, Sanomura $Y$, Arihiro K, et al. Clinical validity of the expanded criteria for endoscopic resection of undifferentiated-type early gastric cancer based on long-term outcomes. Surg Endosc. 2014;28:639-47.
3. Choi MS, Hong SJ, Han JP, Song JY, Kim DY, Seo SW, et al. Therapeutic outcomes of endoscopic submucosal dissection in undifferentiated-type early gastric cancer. Korean J Gastroenterol. 2013;61:196-202 (in Korean).

4. Wen J, Linghu EQ, Yang YS, Liu QS, Yang J, Lu ZS. Associated risk factor analysis for positive resection margins after endoscopic submucosal dissection in early-stage gastric cancer. J BUON. 2015;20:421-7.

5. Kakushima N, Ono H, Tanaka M, Takizawa K, Yamaguchi Y, Matsubayashi $\mathrm{H}$. Factors related to lateral margin positivity for cancer in gastric specimens of endoscopic submucosal dissection. Dig Endosc. 2011;23:227-32.

6. Yun GW, Kim JH, Lee YC, Lee SK, Shin SK, Park JC, et al. What are the risk factors for residual tumor cells after endoscopic complete resection in gastric epithelial neoplasia? Surg Endosc. 2015;29:487-92. 